\title{
NEWLY-GRADUATED MEDICAL DOCTORS AS NEAR-PEER TUTORS FOR PREPARING NATIONAL LICENSING EXAMINATION: A CASE REPORT
}

\author{
Prattama Santoso Utomo ${ }^{1 *}$, Arta Farmawati², James Degnan ${ }^{3}$, Rachmadya Nur Hidayah ${ }^{1}$, \\ Rilani Riskiyana ${ }^{1}$, Gandes Retno Rahayu ${ }^{1}$ \\ ${ }^{1}$ Department of Medical Education and Bioethics, Faculty of Medicine, Public Health and Nursing, Universitas Gadjah Mada, \\ Yogyakarta - INDONESIA \\ ${ }^{2}$ Department of Biochemistry, Faculty of Medicine, Public Health and Nursing, Universitas Gadjah Mada, Yogyakarta - \\ INDONESIA \\ ${ }^{3}$ Temple University, Philadelphia - USA
}

Submitted: 21 Dec 2020; Final Revision from Author: 21 Feb 2021; Accepted: 24 Feb 2021

\begin{abstract}
Background: Medical students in Indonesia are required to pass a national licensing examination (e.g., UKMPPD) as a requirement of graduation and to obtain their certificate of competence. Medical schools prepared their students based on their needs and capacity. The preparation might use different teaching approaches. Undergraduate medicine program in Universitas Gadjah Mada conducts a national licensing examination preparation program facilitated by both faculty members and peer tutors. The peer tutors are newly graduated medical doctors who were recruited and trained. The use of trained peer tutors in a structured program to prepare high-stake examination such as a national examination is considered novel. This paper aims to describe a peer-assisted learning (PAL) approach used to prepare medical students in facing a national licensing examination.
\end{abstract}

Case Discussion: A preparation program using faculty and peer tutors was deployed to prepare finalyear medical students for facing the Indonesian national licensing examination. The ratio of sessions facilitated by faculty to peer tutors was 1:2. The preparation included CBT and OSCE training. Sessions with faculty used a medium to large class approach while sessions with peer tutors used a small to medium group approach. Through February 2020, 147 students have participated in the program. A questionnaire was developed to measure agreement that the program was successful and if the tutees were satisfied with various aspects of the program. The tutees responded with high rates of satisfaction to most items on the questionnaire (responses for all but one item ranged between $72.1 \%$ and $90.5 \%$ in favorable agreement or satisfaction). The one exception was CBT preparation where the level of satisfaction was lower $(54.4 \%$ rated CBT favorably). Participants highly valued the involvement and the performance of peer tutors.

Conclusion: The use of near-peer assisted learning for national licensing examination preparation has strong potential. Further study is required to investigate the impact of the peer-assisted national licensing examination preparation program on students' achievement and clinical practice.

Keywords: national licensing examination, preparation program, peer tutor, peer-assisted learning

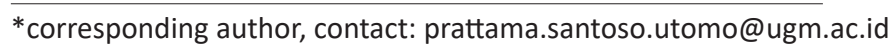




\section{PRACTICE POINTS}

- National licensing examination preparation using a combination of faculty-led sessions and peer tutor-led sessions was perceived as useful and has strong potential for future practice.

- Newly graduated doctors can assist as peer tutors in the national licensing examination preparation program.

\section{INTRODUCTION}

Peer-assisted learning (PAL) is a learning method where students learn from others who are not professional teachers or formal experts. ${ }^{1}$ PAL has been in use since the the time of Plato and is still used in many fields, including medical education. ${ }^{2}$ In medical and health professions education, PAL is applied in both undergraduate and postgraduate setting. PAL is used to facilitate small group discussions, ${ }^{3}$ clinical skills training, ${ }^{4}$ interprofessional education, ${ }^{5}$ test preparation ${ }^{6}$ and clinical simulation. ${ }^{7}$ PAL involves peer learners/tutees and peer teachers/ tutors working together. Peer tutors often are more advanced students or senior students and are often referred to a near-peer tutors because of their closeness in age and level of training.

Literature suggests a range of PAL pedagogical advantages for both peer tutors and tutees. For tutees, the learning process becomes more fun and less threatening compared to professor-led learning due, in part, to the 'social congruence' of the tutees and tutors. ${ }^{8}$ Moreover, 'cognitive congruence' between tutors and tutees often results in instruction that is easier to deliver and easier for the tutees to understand. ${ }^{8}$ The peer tutors also benefit from the PAL activity. Peer tutors' understanding and mastery improved as they teach. The benefit of peer teaching is also congruent with Edgar Dale's "Pyramid" theory of learning, ${ }^{9}$ which states that the best learning acquisition may be achieved through teaching, and also reported by some experiments..$^{10}$ The PAL process also assists peer tutors to practice better management and communication skills. ${ }^{1}$ Peer tutors often express a greater willingness to become medical teachers. ${ }^{1}$

Final-year medical students in Indonesia are required to pass a national licensing examination conducted by the government. The competence certificate will be provided to the graduates only when they pass both the cognitive examination (using MCQsCBT) and the skills examination (using OSCE). The national examination is a high-stake exit exam for all medical students in Indonesia. Faculty of Medicine, Public Health and Nursing at Universitas Gadjah Mada arrange a preparation course for the final-year medical students to help students prepare for the cognitive and skills components of the examination. Preparation sessions are mostly facilitated by peer tutors who are newly-graduated medical doctors. A smaller portion of sessions were facilitated by experts/ specialists in particular areas of medicine. The program is intended to refresh students' knowledge and skills they had learned during their previous years of study. The sessions are not intended to replace the students' previous education experience.

This paper aims to report on the use of near-peer tutors for preparing final-year students facing the Indonesian National Licensing Examination (the UKMPPD). The use of peer-assisted learning in preparing high-stake examinations, such as a national licensing examination might have been reported elsewhere. Nevertheless, a study investigating the learning process and academic benefit behind this approach are novel, especially on attitude of learning prior a high-stake examination. Some evaluation results will be discussed further in this paper. The program evaluation obtained approval from the Human Research Ethics Committee of the Faculty of Medicine, Public Health and Nursing Universitas Gadjah Mada Ref No. KE/FK/0287/EC/2020.

\section{CASE DESCRIPTION}

The undergraduate medicine program of the Faculty of Medicine, Public Health and Nursing Universitas Gadjah Mada conducts a national licensing 
examination preparation program. The program consists of the CBT preparation to assist students with the MCQs-CBT aspect of the examination and with OSCE preparation. The program was not mandatory, but all students were encouraged to join the preparation program. The program length is approximately six weeks and is offered prior to every examination period, as described in Table 1.

Table 1. Preparation program and examination timeline throughout a year

\begin{tabular}{lcccccccccccc} 
& Jan & Feb & Mar & Apr & May & Jun & Jul & Aug & Sep & Oct & Nov & Dec \\
NLEP & $\mathbf{X}$ & $\mathbf{X}$ & & $\mathbf{X}$ & $\mathbf{X}$ & & $\mathbf{X}$ & $\mathbf{X}$ & & $\mathbf{X}$ & $\mathbf{X}$ & \\
UKMPPD & & $\mathbf{X}$ & & & $\mathbf{X}$ & & & $\mathbf{X}$ & & & $\mathbf{X}$ & \\
\hline
\end{tabular}

NLEP: national licensing examination preparation program

UKMPPD: Uji Kompetensi Mahasiswa Program Profesi Dokter, a national licensing examination in Indonesia

The program incorporates various sessions with some sessions facilitated by faculty members/lecturers and other sessions facilitated by peer tutors. A mini CBT examination was performed once a week during the CBT preparation period. OSCE simulation was performed on the first and last day of the OSCE preparation period. The course meets from 4-8 hours a day depending on the schedule and topics discussed. The national examination preparation program consisted of activities structured as in Figure 1.

\begin{tabular}{|c|c|c|c|c|c|c|c|c|c|c|c|c|}
\hline \multirow{3}{*}{ Day } & \multicolumn{8}{|c|}{ MCQs-CBT Preparation } & \multicolumn{4}{|c|}{ OSCE Preparation } \\
\hline & \multicolumn{2}{|c|}{ Week 1} & \multicolumn{2}{|c|}{ Week 2} & \multicolumn{2}{|c|}{ Week 3} & \multicolumn{2}{|c|}{ Week 4} & \multicolumn{2}{|c|}{ Week 5} & \multicolumn{2}{|c|}{ Week 6} \\
\hline & $\mathrm{AM}$ & PM & $\mathrm{AM}$ & PM & $\mathrm{AM}$ & PM & $\mathrm{AM}$ & PM & AM & PM & $\mathrm{AM}$ & PM \\
\hline Mon & \multicolumn{2}{|c|}{ Introduction } & FAC & PT & FAC & PT & FAC & PT & \multicolumn{2}{|c|}{ OSCE Simulation } & PT & DW \\
\hline Tue & FAC & PT & PT & PT & PT & PT & PT & PT & PT & DW & PT & PT \\
\hline Wed & PT & PT & FAC & PT & FAC & PT & FAC & PT & PT & PT & PT & DW \\
\hline Thu & FAC & PT & PT & PT & PT & PT & PT & P & PT & DW & \multicolumn{2}{|c|}{ OSCE Simulation } \\
\hline Fri & PT & MEx & FAC & MEx & FAC & MEx & FAC & MEx & PT & PT & \multicolumn{2}{|c|}{ Wrap-Up } \\
\hline FAC & \multicolumn{4}{|c|}{ Sessions with faculty/lecturer, large group } & PT & \multicolumn{4}{|c|}{ Sessions with peer tutors, small-group } & $\mathrm{AM}$ & \multicolumn{2}{|c|}{ Morning Sessions } \\
\hline MEx & \multicolumn{3}{|c|}{ Mini/Mock CBT examination } & DW & Worksho & with & $y \& p$ & utors & -group & PM & \multicolumn{2}{|l|}{$A$} \\
\hline
\end{tabular}

Figure 1. Structure of the national licensing examination preparation program

Peer tutors were fresh-graduate medical doctors who were recruited by the medical school. All peer tutors passed the national licensing examination and graduated with an outstanding GPA (cumlaude). They are mostly in their internship year. Indonesia applies a one-year internship program for newly-graduated medical doctors as a compulsory requirement to be granted a full register as a medical doctor from the Indonesia Medical Council. The selection process of the peer tutors includes administrative selection and an interview. Selected peer tutors then signed a one- year working contract with the medical school. Peer tutors received an honorarium for every session they facilitated in the preparation course.

The preparation course included materials similar to topics examined in the national licensing examination for both CBT and OSCE. In CBT preparation, sessions with a faculty/lecturer discuss a certain topic that is often based on a set of exercise questions. Sessions with peer tutors tend to focus on exercises and drills on the exercise questions. Peer tutor sessions include in-depth discussions 
and explanations of each topic. During OSCE preparation, faculty/lecturers and peer tutors focus on learning clinical reasoning and prescribing skills without mannequins during the dry workshop (DW). Peer tutors also facilitate small-group skills training sessions in preparation for the OSCE. The ratio of sessions facilitated by faculty/lecturers to peer tutors is approximately $1: 2$. Topics delivered in the national licensing examination preparation course are listed below:

1. CBT Preparation

a. Internal medicine: gastroenterohepatology, infectious disease, hematooncology, endocrinology and metabolic, allergyimmunology, cardiology, pulmonology, nephrology

b. Pediatric medicine: gastroenterohepatology, infectious disease, hematooncology, endocrinology and metabolic, growthdevelopment, social paediatric, allergyimmunology, cardiology, pulmonology, nephrology

c. Surgery: orthopaedics, neurosurgery, surgical oncology, general surgery, urology

d. Obstetrics and gynaecology

e. Otonasolaryngology

f. Opthalmology

g. Dermato-venereology

h. Neurology

i. Psychiatry

j. Forensic and medicolegal

k. Public health: health policy, health financing, epidemiology

1. Biostatistics

2. OSCE Preparation
a. Neurologic system
b. Psychiatry
c. Sense organ system
d. Respiratory system
e. Cardiovascular system
f. Gastrointestinal, hepatobiliary and pancreatic system
g. Kidney and urinary system
h. Reproductive system

i. Endocrine system, metabolism and nutrition

j. Hematology and immune system

k. Musculoskeletal system

1. Integument system

m. Dry workshops: prescribing practice, clinical reasoning

After completing all aspects of the preparation program, participants are invited to join a 2-hours wrap-up session. During wrap-up, a panel of faculty/ lecturers from all departments answer any questions from the participants. Participants may also raise their concerns related to the national licensing examination.

A survey was conducted to evaluate students' perceptions of the national licensing examination preparation program. The survey consisted of 12 items using a 6 level likert-scale where " 6 " is "strongly agree" and " 1 " is "strongly disagree". There were 2 open-ended questions. The open-ended questions as follow:

1. What are your suggestions to improve the national licensing examination preparation program?

2. What are your suggestions to improve peer tutors' role further and in the national licensing examination program?

All items in the survey were reviewed by faculty members and peer tutors involved in the program to ensure face validity. Wording and sequence changes were performed to increase readability of the final questionnaire items.

The survey was distributed online using a GoogleForms application that required students to answer every question. The survey was conducted in February 2020 after the UKMPPD examination was completed. A total of 147 participants responded to the questionnaire (100\% response rate). The quantitative results of the evaluation are described in Table 2 below. 
Table 2. Quantitative evaluation responses $(\mathrm{N}=147)$

\begin{tabular}{|c|c|c|c|c|c|c|c|c|}
\hline \multirow{2}{*}{ Questionnaire Items } & \multicolumn{6}{|c|}{ Number of Responses* [n [\%)] } & \multirow{2}{*}{$\begin{array}{c}\operatorname{Mean}^{\wedge} \\
(\mathrm{SD})\end{array}$} & \multirow{2}{*}{$\mathrm{AR}^{*}$} \\
\hline & 1 & 2 & 3 & 4 & 5 & 6 & & \\
\hline $\begin{array}{l}\text { The NLEP assisted me in facing } \\
\text { CBT exam }\end{array}$ & $\begin{array}{c}4 \\
(2.7)\end{array}$ & $\begin{array}{c}15 \\
(10.2)\end{array}$ & $\begin{array}{c}22 \\
(15.0)\end{array}$ & $\begin{array}{c}53 \\
(36.1)\end{array}$ & $\begin{array}{c}45 \\
(30.6)\end{array}$ & $\begin{array}{c}8 \\
(5.4)\end{array}$ & $\begin{array}{l}3.98 \\
(1.16)\end{array}$ & $72.1 \%$ \\
\hline $\begin{array}{l}\text { The NLEP assisted me in facing } \\
\text { OSCE exam }\end{array}$ & $\begin{array}{c}4 \\
(2.7)\end{array}$ & $\begin{array}{c}6 \\
(4.1)\end{array}$ & $\begin{array}{c}11 \\
(7.5)\end{array}$ & $\begin{array}{c}34 \\
(23.1)\end{array}$ & $\begin{array}{c}68 \\
(46.3)\end{array}$ & $\begin{array}{c}24 \\
(16.3)\end{array}$ & $\begin{array}{l}4.55 \\
(1.14)\end{array}$ & $85.7 \%$ \\
\hline $\begin{array}{l}\text { Faculty/lecturers adequately } \\
\text { facilitated CBT preparation }\end{array}$ & $\begin{array}{c}3 \\
(2.0)\end{array}$ & $\begin{array}{c}4 \\
(2.7)\end{array}$ & $\begin{array}{c}21 \\
(14.3)\end{array}$ & $\begin{array}{c}39 \\
(26.5)\end{array}$ & $\begin{array}{c}63 \\
(42.9)\end{array}$ & $\begin{array}{c}17 \\
(11.6)\end{array}$ & $\begin{array}{l}4.40 \\
(1.08)\end{array}$ & $81.0 \%$ \\
\hline $\begin{array}{l}\text { Faculty/lecturers adequately } \\
\text { facilitated OSCE preparation }\end{array}$ & $\begin{array}{c}0 \\
(0.0)\end{array}$ & $\begin{array}{c}3 \\
(2.0)\end{array}$ & $\begin{array}{c}14 \\
(9.5)\end{array}$ & $\begin{array}{c}42 \\
(28.6)\end{array}$ & $\begin{array}{c}73 \\
(49.7)\end{array}$ & $\begin{array}{c}15 \\
(10.2)\end{array}$ & $\begin{array}{l}4.56 \\
(0.88)\end{array}$ & $88.4 \%$ \\
\hline $\begin{array}{l}\text { Peer tutors adequately facilitated } \\
\text { learning activities }\end{array}$ & $\begin{array}{c}5 \\
(3.4)\end{array}$ & $\begin{array}{c}8 \\
(5.4)\end{array}$ & $\begin{array}{c}19 \\
(12.9)\end{array}$ & $\begin{array}{c}48 \\
(32.7)\end{array}$ & $\begin{array}{c}60 \\
(40.8)\end{array}$ & $\begin{array}{c}7 \\
(4.8)\end{array}$ & $\begin{array}{l}4.16 \\
(1.11)\end{array}$ & $78.2 \%$ \\
\hline $\begin{array}{l}\text { Dry workshops were effective to } \\
\text { prepare OSCE }\end{array}$ & $\begin{array}{c}2 \\
(1.4)\end{array}$ & $\begin{array}{c}10 \\
(6.8)\end{array}$ & $\begin{array}{c}16 \\
(10.9)\end{array}$ & $\begin{array}{c}34 \\
(23.1)\end{array}$ & $\begin{array}{c}57 \\
(38.8)\end{array}$ & $\begin{array}{c}28 \\
(19.0)\end{array}$ & $\begin{array}{l}4.48 \\
(1.20)\end{array}$ & $81.0 \%$ \\
\hline OSCE simulations were effective & $\begin{array}{c}1 \\
(0.7)\end{array}$ & $\begin{array}{c}6 \\
(4.1)\end{array}$ & $\begin{array}{c}11 \\
(7.5)\end{array}$ & $\begin{array}{c}26 \\
(17.7)\end{array}$ & $\begin{array}{c}69 \\
(46.9)\end{array}$ & $\begin{array}{c}34 \\
(23.1)\end{array}$ & $\begin{array}{l}4.76 \\
(1.06)\end{array}$ & $87.8 \%$ \\
\hline $\begin{array}{l}\text { CBT preparation materials were } \\
\text { adequate }\end{array}$ & $\begin{array}{c}2 \\
(1.4)\end{array}$ & $\begin{array}{c}8 \\
(5.4)\end{array}$ & $\begin{array}{c}15 \\
(10.2)\end{array}$ & $\begin{array}{c}43 \\
(29.3)\end{array}$ & $\begin{array}{c}61 \\
(41.5)\end{array}$ & $\begin{array}{c}18 \\
(12.2)\end{array}$ & $\begin{array}{c}4.41 \\
(1.09)\end{array}$ & $83.0 \%$ \\
\hline $\begin{array}{l}\text { OSCE preparation materials were } \\
\text { adequate }\end{array}$ & $\begin{array}{c}1 \\
(0.7)\end{array}$ & $\begin{array}{c}3 \\
(2.0)\end{array}$ & $\begin{array}{c}10 \\
(6.8)\end{array}$ & $\begin{array}{c}27 \\
(18.4)\end{array}$ & $\begin{array}{c}82 \\
(55.8)\end{array}$ & $\begin{array}{c}24 \\
(16.3)\end{array}$ & $\begin{array}{l}4.76 \\
(0.93)\end{array}$ & $90.5 \%$ \\
\hline $\begin{array}{l}\text { CBT preparation met my } \\
\text { expectation }\end{array}$ & $\begin{array}{c}12 \\
(8.2)\end{array}$ & $\begin{array}{c}14 \\
(9.5)\end{array}$ & $\begin{array}{c}41 \\
(27.9)\end{array}$ & $\begin{array}{c}30 \\
(20.4)\end{array}$ & $\begin{array}{c}43 \\
(29.3)\end{array}$ & $\begin{array}{c}7 \\
(4.8)\end{array}$ & $\begin{array}{c}3.67 \\
(1.34)\end{array}$ & $54.4 \%$ \\
\hline $\begin{array}{l}\text { OSCE preparation met my } \\
\text { expectation }\end{array}$ & $\begin{array}{c}6 \\
(4.1)\end{array}$ & $\begin{array}{c}6 \\
(4.1)\end{array}$ & $\begin{array}{c}24 \\
(16.3)\end{array}$ & $\begin{array}{c}35 \\
(23.8)\end{array}$ & $\begin{array}{c}61 \\
(41.5)\end{array}$ & $\begin{array}{c}15 \\
(10.2)\end{array}$ & $\begin{array}{l}4.25 \\
(1.21)\end{array}$ & $75.5 \%$ \\
\hline $\begin{array}{l}\text { Peer tutors should be involved in } \\
\text { NLEP }\end{array}$ & $\begin{array}{c}6 \\
(4.1)\end{array}$ & $\begin{array}{c}8 \\
(5.4)\end{array}$ & $\begin{array}{c}16 \\
(10.9)\end{array}$ & $\begin{array}{c}40 \\
(27.2)\end{array}$ & $\begin{array}{c}58 \\
(39.5)\end{array}$ & $\begin{array}{c}19 \\
(12.9)\end{array}$ & $\begin{array}{c}4.31 \\
(1.23)\end{array}$ & $79.6 \%$ \\
\hline
\end{tabular}

NLEP: national licensing examination preparation program

${ }^{*}$ Responses: 1: strongly disagree, 2: disagree, 3: slightly disagree, 4: slightly agree, 5: agree, 6: strongly agree

$\wedge$ Maximum possible Mean was 6.0

${ }^{\#} \mathrm{AR}$ : agreement rate, based on the total proportion of slightly agree-agree-strongly agree responses

Alongside the quantitative data shown in Table 1 , the evaluation obtained qualitative comments and suggestions from all 147 participants/students regarding the national licensing examination preparation program. The summary of qualitative responses from the participants is explained in Table 3.

Table 3. Summary of qualitative evaluation responses

\section{Questionnaire Items}

Suggestions for improving the nationa licensing examination preparation program

\section{Summary of Responses}

- Avoid postponements, reschedules and class delays

- Schedules should be fixed and consistent

- Case-based materials are more preferred than theories and concepts

- Smaller classes were more productive and effective

- Evening sessions should be avoided to allow adequate self-study 
- Sessions should focus on an in-depth discussion of question items to understand related concepts

- Peer tutors should be available to fill in when the lecturers are absent

- OSCE simulation sessions were helpful

- Peer tutors might replace lecturers whenever it is required

- Question items for the exercise should be more vary

- Senior lecturers might be replaced by juniors or peer tutors

- Sessions with faculty members should only focus on difficult concepts and cases

\begin{tabular}{ll}
\hline Suggestions for & - Peer tutors could be more interactive and attractive \\
enhancing peer tutors' & - Peer tutors were helpful, patient and reliable \\
performance and & - Peer tutors should also teach tips to solve questions efficiently \\
role in the national & - References referred by peer tutors should be standardized \\
licensing examination & - Peer tutors should have similar perceptions in concepts they teach \\
preparation program & - Small-group sessions with peer tutors were highly appreciated \\
& - Peer tutors should develop item bank to ensure a variety of the exercise questions \\
& - Peer tutors should not only be smart but also capable of performing learning facilitation \\
& - The medical school should provide an appropriate honorarium to peer tutors. Hence, \\
& they will work their best.
\end{tabular}

\section{DISCUSSION}

This paper describes a preparation program for a national licensing examination which incorporates a substantial portion of sessions facilitated by peer tutors. The overall quantitative evaluation showed positive responses with a high agreement (>70\%) on 11 of 12 aspects. For one aspect (participants' expectation on the CBT preparation) showed lower agreement (54.4\%). Participants perceived that OSCE preparation was relatively adequate and helpful. The quantitative findings were further confirmed with the qualitative/open-ended responses. More suggestions for improvement were raised for the CBT-related items. These findings are consistent with the results of the national licensing examination of the evaluated cohorts, as reported by the national licensing examination committee. ${ }^{11}$

Participants perceived that small-class sessions with a smaller number of students were most helpful and preferred. Small-group class is defined as a learning group with a maximum of 10-12 students. ${ }^{12}$ Smallgroups allow students to interact, encourage active learning, and provide more in-depth facilitation. Other studies have reported that small-class sessions enable students to learn more complex concepts and help to better explain and clarify difficult topics and issues. ${ }^{13}$ Hence, students' perceptions obtained from the program evaluation are relevant as the program aims to not only deliver basic concepts but to pursue deeper understanding.

The national examination preparation program employs peer tutors to facilitate a substantial amount of sessions. Overall, based in the quantitative response, students appreciated the peer tutors' performance and their role in the preparation program. Based on the qualitative responses, students even suggested that peer tutors could replace lecturers to avoid session reschedules and delays. The findings are relevant to the reports in the literature suggesting peer-assisted learning might be as effective as teacher-led learning. ${ }^{14,15}$ It is also reported that students enjoyed sessions with peer tutors more as the sessions were perceived to be safe and relaxing. ${ }^{16}$ Nonetheless, there is a need to ensure that peer tutors are trained properly before engaging learners in peer-assisted learning activities. ${ }^{17}$ The process of learning facilitation might be facilitated by the use of both complex and simple learning media, as reported that sophisticated and conventional learning media both have their own benefits. ${ }^{18}$

This case-study reported evaluation on the satisfaction and perceived attitude level (Kirkpatrick levels 1 and 2A). ${ }^{19}$ There is a need to evaluate students' 
achievement (e.g., national licensing examination scores) to gain a higher level of evidence to measure the efficacy of the program. Evaluation from other points of view (e.g., faculty members and peer tutors) should be undertaken to gain a complete picture for the program evaluation. Nevertheless, the national licensing preparation program was well received by the students/participants.

\section{CONCLUSION}

This paper reported that newly-graduated medical doctors are perceived positively as peer tutors in a national licensing examination preparation program by participants. A national licensing examination preparation program using the reported model was overall well-received. There is a need to improve the program, particularly to avoid reschedules and delays during sessions, where peer tutors might be employed to help minimizing respective complaints and concerns.

\section{RECOMMENDATION}

Involving newly-graduated medical doctors as peer tutors is a potential approach to strenghten national licensing examination preparation. Proper training and rewards for the peer tutors should be arranged in advance to ensure the program's quality. Medical schools should improve their educational quality and process, to not solely depend on preparation programs to improve student outcomes.

Further research is needed to determine what effect near-peer assisted learning has on student learning and on the success students have in passing high stakes examinations. Given that the peer-tutor approach is effective, more work is needed to find ways to recruit, train, and reward medical school graduates who opt to become peer tutors.

\section{ACKNOWLEDGEMENT}

The authors highly appreciated all students who participated in the program evaluation. The program evaluation is a component of the corresponding author's FAIMER Fellowship Project. The project received a research grant from the Faculty of
Medicine, Public Health and Nursing Universitas Gadjah Mada (Dana Masyarakat 2020).

\section{COMPETING INTEREST}

There authors delare that there is no competing interests related this study. This report has not been submitted or being reviewed in other scientific journals.

\section{LIST OF ABBREVIATIONS}

PAL : peer-assisted learning

NLEP : national licensing examination preparation program

OSCE : objective structured clinical examination

CBT : computer-based test

MCQs : multiple-choice questions

GPA : grade point average (in Bahasa Indonesia: indeks prestasi kumulatif)

\section{AUTHORS' CONTRIBUTION}

Prattama Santoso Utomo - project planning, data collection tools development, data collection, data analysis, manuscript and report draft, manuscript review and finalization, manuscript submission

Arta Farmawati - project planning, data collection tools development, data collection, manuscript review and finalization

James Degnan - project planning, data collection tools development, manuscript review and finalization

Rachmadya Nur Hidayah - project planning, data collection, manuscript and report draft, manuscript review and finalization

Rilani Riskiyana - project planning, data collection, manuscript and report draft, manuscript review and finalization

Gandes Retno Rahayu - project planning, manuscript and report draft, manuscript review and finalization

\section{REFERENCES}

1. Herrmann-Werner A, Gramer R, Erschens R, Nikendei C, Wosnik A, Griewatz J, et al. 
Peer-assisted learning (PAL) in undergraduate medical education: An overview. Z Evid Fortbild Qual Gesundhwes. 2017;121:74-81.

2. Olaussen A, Reddy P, Irvine S, Williams B. Peer-assisted learning: time for nomenclature clarification. Medical Education Online. 2016;21(1):30974.

3. Zijdenbos IL, de Haan MC, Valk GD, ten Cate OT. A student-led course in clinical reasoning in the core curriculum. IJME. 2010;1:42-6.

4. Saputra O, Widyandana, Hadianto T. Persepsi terhadap 'training from senior student' dalam penguasaan keterampilan klinik. JPKI. 2014;3(2):108-19.

5. Carr SE, Brand G, Wei L, Wright H, Nicol P, Metcalfe $\mathrm{H}$, et al. "Helping someone with a skill sharpens it in your own mind": a mixed method study exploring health professions students experiences of Peer Assisted Learning (PAL). BMC Med Educ. 2016;16:48.

6. Aba Alkhail B. Near-peer-assisted learning (NPAL) in undergraduate medical students and their perception of having medical interns as their near peer teacher. Med Teach. 2015;37 Suppl 1:S33-9.

7. House JB, Choe $\mathrm{CH}$, Wourman HL, Berg KM, Fischer JP, Santen SA. Efficient and Effective Use of Peer Teaching for Medical Student Simulation. West J Emerg Med. 2017; 18(1):137-41.

8. Lockspeiser TM, O'Sullivan P, Teherani A, Muller J. Understanding the experience of being taught by peers: the value of social and cognitive congruence. Adv Health Sci Educ Theory Pract. 2008;13(3):361-72.

9. Masters K. Edgar Dale's Pyramid of Learning in medical education: a literature review. Med Teach. 2013;35(11):e1584-93.

10. Peets AD, Coderre S, Wright B, Jenkins D, Burak K, Leskosky $\mathrm{S}$, et al. Involvement in teaching improves learning in medical students: a randomized cross-over study. BMC Med Educ. 2009;9:55-.
11. PNUKMPPD. Umpan Balik UKMPPD Periode Agustus 2019 untuk Institusi: Universitas Gadjah Mada. Jakarta: PNUKMPPD Kemendikbud; 2019.

12. Mohanna K, Cottrell E, Wall D, Chambers R. Teaching made easy: a manual for health professionals. 3rd ed. Oxford: Radcliffe Publishing; 2011.

13. Yap R, Moreira A, Wilkins S, Reeves F, Levinson M, McMurrick P. Suturing in small group teaching settings: a modification to Peyton's fourstep approach. Med Sci Educ. 2016;26(4):57580.

14. Tolsgaard MG, Gustafsson A, Rasmussen MB, Hoiby P, Muller CG, Ringsted C. Student teachers can be as good as associate professors in teaching clinical skills. Med Teach. 2007;29(6):553-7.

15. Weyrich P, Celebi N, Schrauth M, Moltner A, Lammerding-Koppel M, Nikendei C. Peerassisted versus faculty staff-led skills laboratory training: a randomised controlled trial. Med Educ. 2009;43(2):113-20.

16. Hill E, Liuzzi F, Giles J. Peer-assisted learning from three perspectives: student, tutor and coordinator. Clin Teach. 2010;7:244-6.

17. Abay ES, Turan S, Odabasi O, Elcin M. Who Is the Preferred Tutor in Clinical Skills Training: Physicians, Nurses, or Peers? Teach Learn Med. 2017;29(3):247-54.

18. Utomo PS, Shitarukmi S, Kurniawati N, Widyandana W. Comparing The Effectiveness of LED TV/LCD and Whiteboard as a Learning Media in PBL Tutorial Discussion in a Medical School at Indonesia. Jurnal Pendidikan Kedokteran Indonesia: The Indonesian Journal of Medical Education. 2019;8(3):129-35.

19. Morrison J. Evaluation. In: Cantillon P, Wood $\mathrm{D}$, editors. $\mathrm{ABC}$ of learning and teaching in medicine. Hoboken: John Wiley \& Sons Inc; 2010. 